\title{
PRIMER REGISTRO DE AKYMNOPELLIS CHILENSIS (GERVAIS, 1847) (SCOLOPENDRIDAE, SCOLOPENDROMORPHA, CHILOPODA) EN EL EXTREMO SUR DE CHILE
}

\section{FIRST RECORD OF AKYMNOPELLIS CHILENSIS (GERVAIS, 1847) (SCOLOPENDRIDAE, SCOLOPENDROMORPHA, CHILOPODA) AT THE SOUTHERN TIP OF CHILE}

\author{
Emmanuel Vega-Román ${ }^{1,2}$, Víctor H. Ruiz ${ }^{1}$, Patricia Arancibia-Ávila $\&$ R. Soto ${ }^{1,3}$
}

Los Scolopendromorpha son los más voraces depredadores dentro de los Quilópodos al alimentarse de vertebrados como anfibios, reptiles o Quirópteros (Butler, 1970; Molinari et al. 2005). $\mathrm{Su}$ diversidad global alcanza las 700 especies, distribuyéndose en casi todo el mundo a excepción de las zonas polares (Edgecombe \& Koch, 2008). Los adultos pueden alcanzar tamaños considerables llegando a medir $30 \mathrm{~cm}$ de largo (Molinari et al. 2005).

El primer registro de un Scolopendromorpha en Chile fue realizado por Gervais (1847) quien describió a Scolopendra chilensis (Gervais, 1847) y Scolopendra pallida Gervais, 1847. Posterior a este hallazgo siguieron los estudios de Silvestri (1899, 1905), Porter (1899, 1911, 1912), Verhoeff (1924, 1939), Chamberlin (1955), Silva \& Avalos (1974), Sielfeld (2002) ${ }^{5}$ y Vega-Román et al. (2011a).

Dentro de este orden, en Chile, se registran a las Familias Cryptopidae y Scolopendridae. Esta última contiene a las especies Cormocephalus pallidus Silvestri, 1899, Akymnopellis laevigata (Porat, 1876), Akymnopellis platei (Attems, 1903) y Akymnopellis chilensis (Gervais, 1847) (Fig. 1 A-D), siendo esta común en el país al documentarse desde Copiapó a Villarrica (Gervais, 1847; Silvestri, 1899; Chamberlin, 1955; Sielfeld, 2002). Sin embargo, y a pesar de su alto número de registros, nunca ha sido documentada en el extremo sur del país.

En el presente trabajo se entregan los primeros registros de la Familia Scolopendridae en el extremo Sur de Chile, al documentar a A. chilensis en el Parque Nacional Torres del Paine.

\footnotetext{
Universidad de Concepción, Facultad de Ciencias Naturales y Oceanográficas.

Programa de Magíster en Enseñanza de las Ciencias

Programa de Doctorado en Sistemática y Biodiversidad

Departamento de Ciencias Básicas, Universidad del Bio Bio, Chillan, Chile

Clase Chilopoda. Guías de identificación de la biodiversidad de fauna chilena. Apuntes de zoología. Universidad Arturo Prat.

Iquique, Chile. 5 pp.
} 

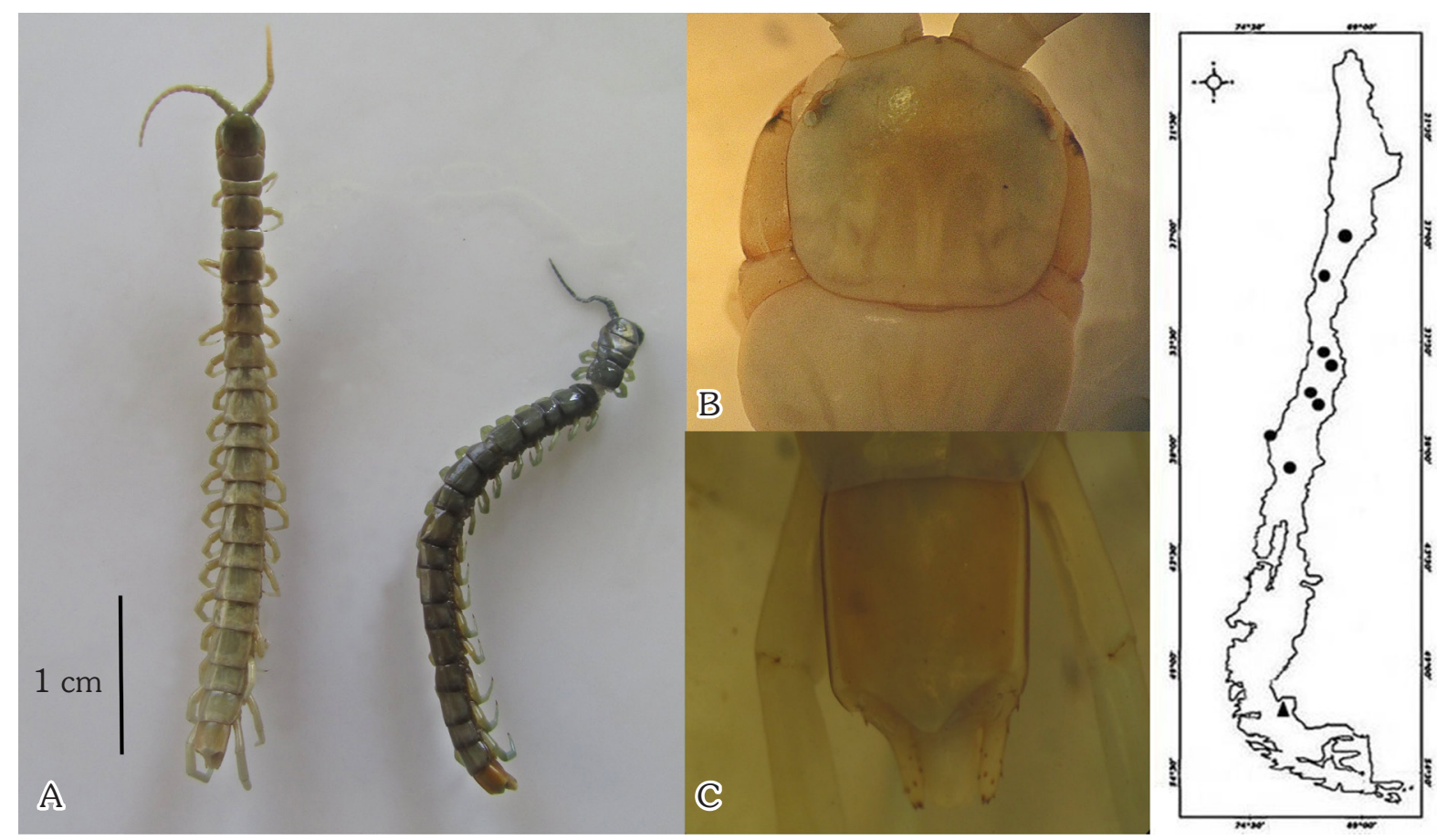

Fig.1. Akymnopellis chilensis. A) Ejemplares recolectados en el Parque Nacional Torres del Paine. B) Placa cefálica superpuesta al primer tergito. C) Tergito 21 sin sutura longitudinal. D) Puntos de registro (Triángulo: Nuevo registro; Circulo: Registro anterior).

Material estudiado: 2 ejemplares ô (Fig.1A), Parque Nacional Torres del Paine, cerca del Lago Sarmiento de Gamboa (5102'59.07's; 72³8'12.60'O) 3 - 11 - 2012, M. Marchant. Recolector.

Una vez identificados, ambos ejemplares fueron depositados en el Museo de Zoología de la Universidad de Concepción (MZUC -UCCC), bajo los códigos: 42229 y 42230.

Mediante este trabajo se amplía el rango de distribución de A. chilensis (Copiapó-Villarrica) desde Copiapó hasta Punta Arenas.

Pérez-Schulteiss \& Mosqueira (2009), Faundez (2011), Vega-Román et al. (2011b, 2013), han contribuido, recientemente, al estudio de los miriápodos chilenos aumentando el rango de distribución o reportando diversas especies de miriápodos. La carencia de especialistas en el estudio de estos organismos tiene como consecuencia la falta de publicaciones. Como evidencia de lo anterior, Vega-Román et al. (2011a) reporta un total de sólo 27 publicaciones desde 1847 al 2011 de este grupo. Si se incentivara el estudio de estas poblaciones, lo más probable es que se encuentren más registros, con un aumento de rango de distribución y posiblemente nuevas especies para el país.

\section{LITERATURA CITADA}

Butler, W. H. (1970). A record of an invertebrate preying on a vertebrate. Western Australian National. 11(1): 146.

Chamberlin, R. (1955). Reports of the Lund University Chile Expedition 1948-1949. The Chilopoda of the Lund University and California Academy of Science Expeditions. Acta Universitatis Lundensis N. S. 215(4): 1-44.

Edgecombe, G. \& Koch, M. (2008). Phylogeny of Scolopendromorph centipedes (Chilopoda): morphological analysis featuring characters from the peristomatic area. Cladistics. 24 (1): 872- 901.

Faundez, E. I. (2011). On the presence of the Scutigera coleoptrata (Linnaeus, 1758) 
(Chilopoda: Scutigeromorpha: Scutigeridae) in the Metropolitan Region, Chile. Boletin de la Sociedad Entomológica Aragonesa. 49: 336.

Gervais, P. (1847). Miriápodos. In: C. Gay (ed.). Historia Física y Política de Chile. Zoología (Fauna chilena). 4: 53-72

Molinari, J., Eliecer, E., De Ascensão, A., Arends, A. \& Márquez, R. (2005). Predation by Giant Centipedes, Scolopendra gigantea on three species of Bats in Venezuelan Cave. Caribbean Journal of Science. 41 (2): 340-346.

Pérez - Schulteiss, J. \& Mosqueira, U. (2009). Primer registro Del ciempiés Scutigera coleoptrata (Linnaeus, 1758) en Chile. Boletín de Biodiversidad de Chile. 1 (1): 38-41.

Porter, C. (1899). Introducción al estudio de los miriápodos. Revista Chilena de Historia Natural. 3(6): 63-68.

Porter, C. (1911). Introducción al estudio de los miriápodos. Catálogo de las especies chilenas. Boletín del Museo Nacional de Historia Natural. 4: 16-68.

Porter, C. (1912). Introducción al estudio de los miriápodos. Catálogo de las especies chilenas. Boletín del Museo Nacional de Historia Natural. 4: 16-68.

Silva, F. \& Ávalos, A. (1974). Miriápodos 2: Quilópodos del Parque Nacional Vicente Pérez Rosales. Anales del Museo Nacional de Historia Natural. 8(1): 15-28.

Silvestri, F. (1899). Contribución al estudio de los quilópodos chilenos. Revista Chilena de Historia Natural 3(10-11): 141-152.

Silvestri, F. (1905). Myriapoda: In: L. Plate (ed.). Fauna Chilensis. Dritter Nand, Gustav Fischer Verlag, Jena, pp. 715-769.

Vega-Román, E., Ruiz, V. H. \& Soto, R. (2011) a. Índice bibliográfico de los miriápodos de Chile desde 1874 a 2010. Boletín de la Sociedad de Biología de Concepción (2010-2011). 80: 89-91.

Vega-Román, E., Ruiz, V. H. \& Soto, R. (2011)b. Primer registro de Cryptops patagonicus Meinert, 1886 (Chilopoda: Scolopendromorpha: Cryptopidae) en Chile. BIOCYT. 4(16): 307-310.

Vega-Román, E. \& Ruiz, V. H. 2013. Nuevos registros de Scutigera coleoptrata (Linnaeus, 1758) (Chilopoda: Scutigeromorpha: Scutigeridae) en Chile. Boletín de la Sociedad Entomológica Aragonesa. 52: 297.

Verhoeff, K.W. (1924). Uber Myriapoden von Juan Fernandez und der Osterisel. In: C. Skottsberg (ed.). The Natural History of Juan Fernandez and Easter Island. Volumen 2, Alquimist \& Willsells Boktryckeriab, Upsala, pp. 43-71.

Verhoeff, K.W. (1939). Von Dr. G. H. Schwabe in Chile gesammelte Isopoda terrestria, Diplopoda und Chilopoda. Archiv für Naturgeschichte. (Syst.). 8(2): 301-324. 
